\title{
Developing An Undergraduate Student Research Conference In Business: A Model
}

Cheryl L. Buff, Siena College

Raj Devasagayam, Siena College

\begin{abstract}
AACSB accreditation, a student-centered mission statement, and the continuous quality improvement that most educators engage in have resulted in an increase in student research projects. This presented an opportunity to develop a venue for students to showcase their research. The paper describes a model for a student research conference in business that has resulted in increased student engagement and an increase in student-faculty research collaboration.
\end{abstract}

Keywords: undergraduate student business research, faculty-student collaborative research, faculty-student mentoring, student research conference, student conference planning and implementation

\section{INTRODUCTION}

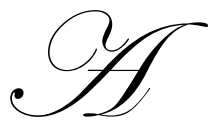

mission statement focused on student centered education and AACSB accreditation - these two factors, as well as the normal continuous quality improvement that most educators engage in, have led to an increase in the number of faculty assigning substantive research projects as part of a course requirement and an increase in the number of primary research based independent studies. Further, as growing emphasis is placed on professional development to maintain the status of "academically qualified," faculty are required to expand, and in some cases to begin, a research agenda. This shift to greater focus on research has also contributed to an increase in faculty-student research relationships that do not result in course credit, but in conference papers and journal articles.

The importance and advantages of undergraduate research are well documented and acknowledged in the natural sciences (Tobochnik, 2001). Therefore, there has been a culture and tradition of engaging undergraduate and graduate students in collaborative research within the natural sciences -- with synergistic learning opportunities for students and faculty alike. Past literature in natural science has made a case for undergraduate research producing better scientists, better graduate students, and consequently better science researchers and educators; in fact, the National Science Foundation has taken proactive steps in organizing conferences and increasing funding for undergraduate research (Doyle 2001, Wieman 2001, Karukstis 2006). Further, the US News and World Report's coveted ranking now devotes attention to undergraduate research in providing valuable input to future students and their families.

In an empirical study based on a sample of over 1100 undergraduate students from 41 states, Lopatto (2004) clearly established the learning gains and satisfaction from education that undergraduate research offers future graduates. The study also underscored the retention of students in their chosen fields long beyond their undergraduate experiences, and further found evidence that such research efforts cemented the path of future success for both gender and ethnic minorities in sciences.

When compared with natural sciences, there is a dearth of undergraduate business research. However, it is generally accepted that undergraduate research offers several learning outcomes that are of the highest order. Advantages often cited include, mentoring relationships between student and faculty leading to enduring life-long 
learning, better undergraduate experience with less dysfunctional behavior (Seaman 2005), higher rates of retention in a major, superior quality of the graduate student pool, enhanced research and analytical skills that bode well for a business career, and a natural sharpening of curiosity and critical thinking that we would like to see in our graduates throughout their professional lives (Elgren and Hensel 2006, Morrison, Oladunjoye, and Onyefulu 2007, Weinstein and Barrette 2007).

Most faculty in undergraduate institutions are aware of all aforementioned advantages, and can testify to some additional advantages as well. However, the commitment to undergraduate business research is in its infancy. Funding for this important pedagogical tool with stellar learning outcomes is scarce and faculty often wonder how to communicate the importance of this activity to the larger academic community on their campus. We believe that while it would be helpful to point out enhanced learning outcomes for undergraduate students, furtherance of scholarly agenda of faculty mentor, and undergraduate research as a source of fundamental knowledge in the field, we would be mistaken to make these the primary agenda to promote undergraduate research. Rather we believe it is more important to establish a return on investment proposition.

It is our experience that showcasing undergraduate research as a fate accompli, with all advantages it has to offer being clearly visible, is the first step in garnering the respect and resources undergraduate research rightfully deserves. In this paper we provide our colleagues with a set of guidelines that would help them showcase undergraduate research on their campus in a meaningful and visible manner. Our primary goal in this paper is to assist colleagues in establishing an undergraduate student research conference on their campus, which would then act as a stimulus and catalyst for undergraduate research opportunities and funding.

\section{Recommended/Ideal Schedule - An Overview}

\section{Summer}

Plan the Conference

Create promotional material

Review budget request with Dean and/or Vice President for Academic Affairs

Plan and produce timeline and logistics of Conference submission

Plan and produce timeline and logistics of Conference reviews

Plan and produce timeline and logistics of participant invitations and confirmations

Fall

Build awareness of the Conference among School of Business faculty

Build awareness of the Conference among School of Business student organizations

Build awareness of the Conference among School of Business students

Update website with information about upcoming conference and "Call for Papers" when available

Identify and contact keynote speaker

Identify student conference assistants to help with Conference logistics and Conference Proceedings

Reserve laptops, projectors, and screens for each track/session

\section{Spring}

Build awareness of the Conference among School of Business alumni

Build awareness of the Conference among business community

Invite submissions

Review submissions

Notify students of acceptance/rejection and finalize presenters

Create proceedings with goal of having them available on the day of the Conference

Plan the Conference logistics

Continued contact with keynote speaker (suggestions for talking points, etc.) 
Identify session chairs

Contact representatives from textbook publishers to ask for gift books

\section{Post Conference Activities}

Schedule date, time, and location for following year's conference

Thank you notes and gifts to reviewers, reception host/hostesses, assistants from information technology

Write article for school newspaper, School of Business newsletter, Academic Affairs newsletter, and alumni news

\section{Observations And Details}

The development of this conference has been and continues to be a learning process. The ideal schedule overview presented above represents the best case scenario and what has been learned through experiences to date. While it is impractical to write about each detail, the overview is expanded below.

\section{Conference Logistics}

The conference begins promptly at 3:00pm with a one minute welcome from the conference co-chair. This is followed by a two-three minute welcome from the College President. The keynote address is next, lasting no more than 15 minutes, including questions and answers. By 3:30, students and faculty are heading to one of the three concurrent sessions. By 4:30, students and faculty reassemble in the main meeting room for brief (one minute) presentations by student clubs officers (e.g., American Marketing Association, Students in Free Enterprise, Accounting Students Association, and Financial Management Student Association). Then awards are presented for best papers and best presentations in each track. Additionally, the faculty mentor for the student earning a best paper award is acknowledged with a certificate and gift book. Finally, the conference co-chair extends a vote of thanks and invites faculty and student presenters to a reception. The conference ends promptly at 5:00.

The primary motivation for keeping the conference moving along is to ensure the participation of students that are not presenting. The past two conferences have had remarkable attendance, with some students standing outside the meeting room to hear the keynote address.

\section{Detail}

- $\quad$ Determine number of tracks

- Identify session chairs for each track (each individual track has a faculty chair and a student chair: faculty chair oversees session and assists student chair; the student chair runs the session, monitors time, and introduces speakers)

- Identify faculty judge for each track (he/she will determine best presentation and convey that information to the conference chair before awards are presented)

- $\quad$ Develop the program brochure and "seat" program

- $\quad$ Coordinate purchase and engraving of best paper and best presentation awards (consider not having names or dates placed on the award so that you can order in bulk and use in subsequent years)

- Coordinate the purchase of Conference "take-aways" (pens and jotters engraved with college name and "Student Conference in Business")

- Coordinate reception (order "finger-food" and beverages)

- $\quad$ Coordinate reception host/hostesses (faculty from School of Business

- $\quad$ Coordinate printing of certificates for faculty research mentors

- $\quad$ Contact publishing representatives to see if they are able to support the conference through monetary donation or gift-book donation (in the past, gift-books have been used successfully. They are given to faculty research mentors, session chairs, best paper judges, best presentation judges, information technology specialists, Vice President of Academic Affairs, President of the College, Dean of School of Business)

- $\quad$ Contact Development Office requesting invitations be sent to select alumni and college supporters 
- $\quad$ Continue to promote event on campus (large posters hung in cafeteria, various places in the School of Business, Academic Affairs website, School of Business website, announcements in class, announcements at faculty meetings)

- $\quad$ Ask faculty in the School of Business to encourage their students to attend the Conference (attach an example of an extra credit assignment to the email sent to faculty)

- Ask presenters to send PowerPoint presentation to student session chair who will load to laptop the morning of the conference

Awards, mementos, and the reception assume that some level of funding is available. (Securing funding became easier after a successful first conference.)

\section{Impact And Outcomes}

The first conference had two tracks (1. Marketing and Management, and, 2. Finance and Accounting). By year 2, the conference expanded to include an Economics track and five additional presentations. The number of faculty research mentors has increased as well. In fact, it is a goal of the conference co-chairs to expand faculty and student participation, and it is this statistic that will be used as a measure of success in the short term.

The conference allows for the recognition of School of Business students that are creating high quality work. Since the conference is announced in many classes when projects are assigned, it is possible that some students will invest more time in a project knowing they have an opportunity to have their work considered for acceptance. For any student continuing on to graduate school, this gives them experience with the research presentation and publication process. The Conference provides an invaluable opportunity for faculty and students to build mentoring scholarly relationships outside the classrooms which may lead to a lifelong learning relationship between them. Finally, the impact on the School of Business has been positive in terms of student engagement, AACSB accreditation, and learning outcomes (Legorreta, Kelley, and Sablynski 2006, Pringle and Michel 2007).

The collaborative model of teaching and learning that such an undergraduate research conference encourages is very experiential and the student learning is phenomenological in nature. The faculty mentor becomes a collaborator in the learning process, and can actually guide the student to learn from the very experience of undertaking a research project from start to finish and then communicating the findings to the larger body of knowledge. The dissemination of knowledge to one's peers is an invaluable part of critical thinking and learning that the student can then employ throughout their graduate programs and their professional careers. A student research conference provides the unique opportunity for our students to experience the thrill (or otherwise) of presenting their learning to the greater good of a learning community.

We have found that the outcomes of this conference are motivational, cognitive, and social. They are motivational in that they encourage other students to undertake undergraduate research upon witnessing the success and accomplishments of their peers. We also find that this extra-classroom experiential learning opportunity motivates the participant in the conference to use their critical thinking and research skills in all the courses they undertake. Cognitively, students and faculty have often commented on the multiplicity of methodology used in undergraduate research papers presented in the conference and the variety of schematic lenses used to study extant business problems - a perspective that a liberal education fosters and encourages. The myopic tunnel vision that a business major could easily develop in a "straight business" program is thus counterbalanced with a healthy respect for divergent views. Socially, Cottell and Millis (1993) posit that collaborative and cooperative learning leads to positive interdependence and individual accountability. A research project that is targeted to be presented to a larger audience for critical review leads to closer faculty student interaction and a heightened sense of accountability for both participants. We have often found a profound sense of pride among caring teachers when their prodigy is acknowledged as having achieved excellence in research. Whelan, Thomas, and Madden (2007) in an empirical investigation found that faculty-student collaborative research produced a higher level of learning, motivation, interest, and skills in student collaborators than when they undertook research on their own. More interestingly, the faculty collaborators reported a more satisfying and better organized research agenda. A conference of this nature allows the faculty collaborator to gain credit for such research in a tangible manner with more research productivity 
and consequently a better access to the reward system at their institution. Finally, we have seen sea shift in the research culture of our institution as a result of this modest conference. Faculty are more engaged in research conversations in anticipation of this conference and this event unites faculty with divergent research fields with their common love for teaching-learning and the welfare of their students.

In conclusion, it is our hope that this paper facilitates the establishment of an active and productive undergraduate research program at your institution. We hope that our experience will keep you from reinventing the wheel and actually provide you insights that further perfect this proposed model. An undergraduate research program can be a formal reality at our institutions if we indeed are able to underscore the positive learning outcomes of collaborative, participatory, and experiential pedagogical enhancements that this model potentially has to offer.

\section{REFERENCES}

1. Cottell, P. G., and Millis, B.J. (1993). Cooperative Learning Structures in the instruction of Accounting. Issues in Accounting Education, 8, 40-58.

2. Doyle, Michael (2001). Academic Excellence: The Role of Research in physical Sciences at Undergraduate Institutions, ed., Research Corp, Tucson: Arizona.

3. Elgren, Tim and Hensel, Nancy. (2006). Undergraduate Research Experiences: Synergies between Scholarship and Teaching. Peer Review, 8(1), 4-7.

4. Karukstis, Kerry. (2006). A Council on Undergraduate Research Workshop Initiative To Establish, Enhance, and Institutionalize Undergraduate Research. Journal of Chemical Education, 83(12), 17441745 .

5. Legorreta, Leonardo, Kelley, Craig A., and Sablynski, Chris J. (2006). Linking Faculty Development to the Business School's Mission. Journal of Education for Business, 82(1), 3-10.

6. Lopatto, David, (2006). Undergraduate Research as a Catalyst for Liberal Learning. Peer Review, 8(1), 2225.

7. Morrison, James L, Oladunjoye, Ganiyu T., and Onyefulu, Cynthia. (2007). An Assessment of Research Supervision: A Leadership Model Enhancing Current Practices in Business and Management. Journal of Education for Business, 82(4), 212-219.

8. Pringle, Charles and Michel, Mitri. (2007). Assessment Practices in AACSB-Accredited Business Schools. Journal of Education for Business, 82(4), 202-211.

9. Seaman, Barrette. (2005). Binge: What your college student won't tell you. Hoboken, NJ: John Wiley and Sons, Inc.

10. Tobochnik, Jan. (2001). The importance of undergraduate research. American Journal of Physics, Vol. 69 (9).

11. Weinstein, Art, and Barrett, Hilton. (2007). Value Creation in the Business Curriculum: A Tale of Two Courses. Journal of Education for Business, 82(6), 329-336.

12. Whelan, Kevin, Thomas, Jane E. and Madden, Angela M. (2007). Student Research Projects: The Experiences of Student Dietitians, University Faculty Members, and Collaborators. American Dietetic Association. Journal of the American Dietetic Association, 107(9), 1567.

13. Wieman, Carl. (2001). A Modest Proposal: Recruit Undergraduate Majors. APS News, May. 
NOTES 